\title{
Normas de Descrição Arquivística: Uma análise comparativa no âmbito do conteúdo e contexto
}

\section{Norms of archival description: a comparative analysis in the context of content and context}

\author{
Leolíbia Luana Linden | UFSC | leolibialuana@gmail.com \\ Thiago Henrique Bragato Barros | UFPA | thiagobarros@ufpa.br \\ Marisa Bräscher | UFSC | marisa.brascher@gmail.com
}

\begin{abstract}
Resumo: Tem-se a descrição arquivística como função elementar no processo de organização e recuperação de documentos de arquivo. Trata do processo de padronização da descrição e da contribuição da normalização para a recuperação de documentos de arquivo. Apresenta os processos que levaram à normalização e aos respectivos Instrumentos Normativos de Descrição Arquivística (INDA) internacionais e nacionais. Enfatiza a importância de conteúdo e contexto serem contemplados em sua estrutura. Analisa os campos de "Identificação", "Contexto" e "Conteúdo" em INDA com o objetivo de identificar como são percebidos dois preceitos fundamentais para descrição a análise e síntese realizada nos campos de contexto e conteúdo dos respectivos. Fundamenta como o contexto e conteúdo são contemplados nos INDA e tece considerações conceituais acerca da análise. Contribui para a compreensão da padronização e consolidação das questões de contexto e conteúdo no processo de Representação Arquivística.

Palavras-chave: Descrição Arquivística. Normalização. Conteúdo. Contexto.
\end{abstract}

\begin{abstract}
It has been the archival description as an elementary function in the process of organizing and retrieving archival documents. It deals with the process of standardization of the description and the contribution of normalization to the retrieval of archival documents. It presents the processes that have led to the normalization and the respective Normative Instruments of Archival Description (INDA) international and national. It emphasizes the importance of content and context to be contemplated in its structure. It analyzes the fields of "Identification", "Context" and "Content" in INDA with the objective of identifying how two fundamental precepts are perceived to describe the analysis and synthesis carried out in the context and content fields of the respective ones. It bases how the context and content are contemplated in the INDA and weaves conceptual considerations about the analysis. It contributes to the understanding of standardization and consolidation of context and content issues in the Archival Representation process.

Keywords: Archival Description. Normalization. Content. Context.
\end{abstract}




\section{Introdução}

A descrição arquivística cumpre as funções matriciais dos arquivos: 1) preservar e controlar a documentação 2) dar acesso aos documentos de arquivo.

Neste sentido, trata-se de uma das mais fundamentais e importantes funções arquivísticas, que ao longo do tempo cresce em importância e destaque. Seu auge ocorre com o movimento de normalização da descrição arquivística e tem se desenvolvido no decorrer dos últimos 30 anos, buscando facilitar o processo de recuperação da informação por meio da padronização de elementos que possam representar a informação contida nos documentos.

Trata-se conjuntamente com a classificação das atividades que mais podem contribuir e buscar contribuições no contexto da organização do conhecimento. Uma vez que é por meio delas, que os arquivistas pensam metodologicamente a organização do conhecimento arquivístico.

A descrição arquivística proporciona diferentes formas de viabilizar a recuperação da informação, de maneira a possibilitar ao usuário maior satisfação em sua busca.

Para que isso seja possível, a identificação e descrição dos elementos de conteúdo e contexto são substanciais quando se trata de documentos arquivísticos e tratam-se dos campos de maior complexidade no processo de representação nos arquivos.

Com isso, o presente trabalho analisou-se a estrutura de conteúdo e contexto em Instrumentos Normativos de Descrição Arquivística (INDA) nos campos relacionados a "Identificação", "Contexto" e "Conteúdo" identificando seus pontos convergentes e divergentes.

Com isso, este estudo pretende contribuir com aspectos a serem considerados no processo de representação da informação arquivística visando sua recuperação, acesso e preservação. 


\section{Descrição Arquivística}

Para que seja possível representar a informação, é necessário realizar a descrição física e de conteúdo dos objetos informacionais, em que: a descrição física concentra-se no suporte da informação, enquanto a descrição de conteúdo volta-se para o conhecimento registrado neste suporte (BRÄSCHER; CAFÉ, 2008, p.5).

No âmbito dos arquivos, a função de descrição arquivística é uma das mais importantes. É a partir dela que tornamos possivel acessar as informações contidas nos documentos.

A descrição, enquanto função, é provavelmente a de maior impacto na organização de arquivos, uma vez que é a ligação entre os documentos e os usuários (BARROS, 2015).

Agregado à preservação da memória, o conceito de descrição arquivística se desenvolveu sob influências de princípios de proveniência e ordem original estabelecidos em 1841, assumindo a integração das atividades de classificação e descrição. Com isso, diferentes instrumentos de pesquisa foram gerados para facilitar o manuseio e recuperação dos documentos de arquivo (DURANTI, 1993, p.51).

Durante a década de 1980, surge uma pluralidade de interpretações e diferenças em relação aos tipos de instrumentos de pesquisa, mesmo que três conjuntos permaneçam como base para a elaboração:

1. Os guias. Dos quais se diferenciam: o guia-censo, guia de fontes, guia orgânico e guia de arquivos.

2. Os inventários. Dos quais se diferenciam o inventário analítico e o inventário sumário

3. Os catálogos. Dos quais se diferenciam o catálogo de documentos e o catálogo de expedientes (CRUZ MUNDET, 2001, p.272-296, tradução nossa).

Assim, durante a trajetória da descrição muito foram os modelos utilizados para a elaboração dos instrumentos de pesquisa.

O Work Group on Archival Descriptive Standards - do Bureau of Canadian Archivists $(B C A)$-, foi o primeiro grupo de trabalho voltado para a descrição 
normalizada no Canadá, tendo sido estabelecido em 1985, com trabalhos contínuos até a efetiva publicação de uma norma nacional de descrição arquivística. Uma das primeiras atividades do grupo foi a definição, ainda preliminar na época, do que era a descrição de arquivos:

"Descrição é uma função principal no processamento de materiais arquivísticos, cujos produtos são os instrumentos de pesquisa de vários tipos, dando aos administradores controle sobre o acervo e possibilitando aos usuários e arquivistas encontrar informações sobre tópicos particulares" (BCA, 1985, p.9, tradução nossa).

Assim, na prática dos arquivos a descrição esteve presente desde meados do século XIX, porém é só nos anos 1980 que se inicia uma discussão mais ampla dos conceitos e modelos visando refinamento, normalização e aprimoramento da função. O primeiro modelo deste movimento surge em 1986 com a publicação do Manual of Archival Description (MAD) no Reino Unido.

O objetivo da padronização do processo de descrição arquivística estaria diretamente relacionado com a garantia da eficiência e efetividade no processo de pesquisa, otimização do trabalho do arquivista e a familiarização com o acervo que está sendo descrito (FOX, 2007, p.28)

Nesse processo de padronização, as normas de descrição arquivística cumprem relevante papel. Em pesquisa realizada por Linden (2017, p.), são oito normas que foram desenvolvidas de acordo com a realidade de cada país, incluindo a norma internacional de descrição arquivística, ISAD (G), como seguem elencadas no Quadro 1. 


\begin{tabular}{|c|c|}
\hline INDA's & PAÍs \\
\hline Manual Archival Description (MAD) & Reino Unido \\
\hline Rules for Archival Description (RAD) & Canadá \\
\hline $\begin{array}{l}\text { General International Standard } \\
\text { Archival Description (ISAD G) }\end{array}$ & Internacional \\
\hline $\begin{array}{l}\text { Describing Archives: a Content } \\
\text { Standard (DACS) }\end{array}$ & EUA \\
\hline $\begin{array}{l}\text { Norma Española de Descripción } \\
\text { Archivistica (NEDA) }\end{array}$ & Espanha \\
\hline $\begin{array}{l}\text { Norma Brasileira de Descrição } \\
\text { Arquivistica (NOBRADE) }\end{array}$ & Brasil \\
\hline $\begin{array}{l}\text { Orientaçôes para a descrição } \\
\text { arquivistica (ODA) }\end{array}$ & Portugal \\
\hline $\begin{array}{l}\text { Norma Uruguaya de Descripción } \\
\text { Archivistica (NUDA) }\end{array}$ & Uruguai \\
\hline
\end{tabular}

Fonte: LINDEN, 2017.

Para a International Standard Archival Description General(ISAD(G)) (2001, p.11) "o objetivo da descrição arquivística é identificar e explicar o contexto e o conteúdo de documentos de arquivo a fim de promover o acesso aos mesmos.

Haworth (2001), define que os arquivistas pretendem representar 0 conteúdo, a estrutura e o contexto dos documentos no cumprimento da função da descrição arquivística. Em concordância, para a finalidade deste trabalho, compreende-se a relevância do conteúdo e do contexto nessa perspectiva.

Com isso, analisa-se as normas de descrição arquivística por meio da análise de conteúdo proposta por Bardin (2011), aplicada às temáticas de contexto e conteúdo nas áreas de "Identificação", "Contextualização" e "Âmbito e Conteúdo" de cada um dos Instrumentos Normativos de Descrição Arquivística elencados no Quadro 1.

A escolha das áreas de "Identificação", "Contextualização" e "Âmbito e Conteúdo" para a finalidade desta análise, se justifica pelos indicativos da literatura no que se refere a contexto e conteúdo, e pelo fato de serem áreas comuns entre os instrumentos normativos de descrição arquivística. De acordo com Bardin (2011) a metodologia de análise de conteúdo é composta por três fases, sendo elas: (1) préanálise, que seria um primeiro contato com os documentos que irão compor a análise; (2) exploração do material, que possibilitar a exploração dos documentos objetivando elementos de categorização entre eles; e (3) tratamento dos resultados, 
relacionado a interpretações e inferências a partir de análises reflexivas e críticas a respeito das informações identificadas nos documentos.

3 Análise de conteúdo nas áreas de contexto e conteúdo em Instrumentos Normativos de Descrição Arquivística

A seguir encontram-se os resultados obtidos, apresentados em quadros com as respectivas caracterizações de contexto e conteúdo das áreas de "Identificação", “Contextualização" e “Âmbito e Conteúdo" em INDA's.

Nos Apêndices 1 e 2, usa-se a indicação "NSA" (Não Se Aplica) com significado de que não há informações a serem consideradas por parte do INDA acerca da temática em evidência. Já a indicação “NP” (Não Possui) significa que o INDA não contempla em sua estrutura a área prevista para a análise.

\subsection{Conteúdo}

Nesta seção do texto, apresenta-se a caracterização de 'conteúdo' nas respectivas áreas dos INDA's que tratam de Identificação, Contexto e Conteúdo seguida de uma análise sobre o quadro comparativo.

A partir da análise do Apêndice A, percebe-se que a maioria dos INDA's aponta as áreas de Conteúdo e Identificação como indicativas de conteúdo em sua estrutura. São poucos os casos onde a área de Contexto indica elementos de conteúdo.

Em sua forma mais ampla, nos INDA's contemplados por este estudo, o conteúdo é representado pelo assunto do documento, pela tipologia documental, pelo produtor do documento e pelas funções e atividades que geraram os documentos.

\subsection{Contexto}

Nesta seção do texto, apresenta-se a caracterização de 'contexto' nas respectivas áreas dos INDA's que tratam de Identificação, Contexto e Conteúdo seguida de uma análise sobre o quadro comparativo. 
A partir da análise do Apêndice 2, percebe-se que a maioria dos INDA's aponta a área de Contexto como indicativa da ocorrência de contexto em sua estrutura. $O$ único caso omisso seria o da MAD, que além da área de Contexto, revela a área de Identificação como forma de representar o contexto por meio do Título do documento.

Em sua forma mais ampla, nestes INDA's, o contexto é representado apenas pela área de Contexto por meio dos elementos de: produtor do documento, história arquivística ou custodial, assim como história administrativa da instituição e/ou pessoa que gerou os documentos.

É perceptível por meio desta análise que as normas de descrição, de um modo geral, contemplam os campos de conteúdo e contexto, embora exista uma pluralidade de usos principalmente em relação ao conteúdo. Não existe um consenso do que deve ser descrito no âmbito de ambos os campos. Em alguns casos, coloca-se informações vinculadas aos princípios arquivísticos, em outras informações vinculadas ao assunto dos documentos e informações vinculadas aos processos de indexação.

É fundamental que a área compreenda e sinalize de forma clara nos INDA's, o que deve ser redigido em todos os campos dos instrumentos de pesquisa.

A descrição deve refletir a estrutura do órgão produtor e o contexto de produção documental, porém, considerando a complexidade das instituições e necessidades de acesso, é necessário contemplar ainda aspectos relacionados à tematicidade dos documentos.

\section{Considerações}

De acordo com os elementos indicados por cada um dos Instrumentos Normativos de Descrição Arquivística, conteúdo pode ser representado por: assunto, tipologia, funções, estrutura, forma, gênero e localidades geográficas; já o contexto, pode ser representado por: produtor, história arquivística ou custodial, história administrativa e o título do documento. 
Nota-se que a ocorrência sobre conteúdo é mais comum entre os elementos de descrição quando comparado a contexto. Com base nisso, pode-se inferir que a maior parte dos elementos representam conteúdo, quando na verdade, deveria representar contexto.

Entretanto, acredita-se que os demais elementos, que não foram analisados, mas que compunham as áreas de Identificação, Contexto e Conteúdo também possam representar a proveniência e os assuntos na descrição arquivística.

O baixo índice de elementos de descrição que sejam comuns entre conteúdo e contexto é perceptível. O que nos chama atenção para a necessidade de perceber outros pontos de descrição que possam representar conteúdo e contexto de documentos concomitantemente, aumentando a possibilidade de recuperação da informação.

Observa-se que, por mais que a tentativa seja de padronização dos campos e elementos para a descrição arquivística, nem todos os Instrumentos Normativos de Descrição Arquivística considerados neste estudo possuem uma estrutura padrão, o que até esta pesquisa era fato imaginado e discutido porém não fundamentado ou explorado na literatura da área.

Ponderando os aspectos considerados a partir desta análise, ressalta-se a importância de estudos e análises voltadas ao processo de normalização da descrição arquivística buscando a excelência e eficiência do serviço de acesso a informação e aprofundamento dos instrumentos de descrição.

\section{Referências}

ARCHIVO GENERAL DE LA NACIÓN. Norma Uruguaya de Descripción Archivística/Archivo General de la Nación. Montevideo: AGN,2016, 86 p. Disponível em: < http://www.agn.gub.uy/pdf/nudacontapa.pdf > Acesso em: 16 maio 2017.

BARDIN, L. Análise de conteúdo. São Paulo: Edições 70. 2011.

BARROS, Thiago Henrique Bragato. Uma trajetória da arquivística a partir da análise do discurso: Inflexões histórico-conceituais. 1. ed. São Paulo: Ed da Unesp, 2016. v. 1. $267 p$. 
BRASCHER, M.; CAFÉ, L. Organização da informação ou organização do conhecimento?. In: ENCONTRO NACIONAL DE PESQUISA EM CIÊNCIA DA INFORMAÇÃO, 9., 2008, São Paulo. Anais... São Paulo: ENANCIB, 2008. p. 1-14.

COOK, Michael; GRANT, Kristina. A manual o archival description. London: The Society Archivists, 1986. 197p.

CRUZ MUNDET, José R. Manual de Archivística. Madrid: Fundación Germán Sánchez Ruipérez, 2001.

DIRECÇÃO GERAL DE ARQUIVOS. PROGRAMA DE NORMALIZAÇÃO DA DESCRIÇÃO EM ARQUIVO; GRUPO DE TRABALHO DE NORMALIZAÇÃO DA DESCRIÇÃO EM ARQUIVO - Orientações para a descrição arquivística. 2.. $v$. Lisboa: DGARQ, 2007. 325 p. Disponível em: <http://antt.dglab.gov.pt/wpcontent/uploads/sites/17/2008/09/oda1_2_3.pdf> Acesso em: 16 maio 2017.

DURANTI, L.Origin and development of the concept of archival description. Archivaria: the journal of the Association of Canadian Archivists, Ottawa, n.35, p.47-54, 1993.

FOX, Michael. Por que precisamos de normas. Acervo: revista do Arquivo Nacional, Rio de Janeiro, v.20, n.1-2, p. 23-30, jan./dez., 2007. Disponível em: http://revistaacervo.an.gov.br/seer/index.php/info/article/view/127 . Acesso em 06 mai. 2015. ISAD(G): Norma Internacional de Descrição Arquivística. 2.ed. Rio de Janeiro: Arquivo Nacional, 2000. (Publicações técnicas, n. 49). Disponível em: <http://www.conarq.arquivonacional.gov.br/Media/publicacoes/isad_g_2001.pdf >. Acesso em: 01 maio 2017.

HAWORTH, Kent M. Archival description: content and context: in search of structure. In: PITTI, Daniel V.; DUFF, Wendy M. (Orgs.). Encoded Archival Description on the Internet. New York: The Haworth Information Press, 2001.

LINDEN, Leolíbia Luana. O tratamento temático da informação em instrumentos normativos de descrição arquivística. 2017. 80p. Dissertação (Mestrado em Ciência da Informação) - Universidade Federal de Santa Catarina, Florianópolis, SC.

MINISTERIO DE CULTURA. Norma Española de Descripción Archivística. Espanha, 2006. 124p. Disponível em:

http://www.aefp.org.es/NS/Documentos/NormasDecscriptivas/NEDA/NEDA_v1_20 05 completa.pdf Acesso em: 16 maio 2017.

RULES for archival description. Ottawa: Planning Committee on Descriptive Standards/Bureau of Canadian Archivists, 1990. Revised version: July 2008. Disponível em : http://www.cdncouncilarchives.ca/archdesrules.html . Acesso em: 
16 maio 2017.

THE SOCIETY OF AMERICAN ARCHIVISTS. Describing archives: a content standard. Chicago: The Society of American Archivists, 2008. 281p. 
Apêndice A - Caracterização de 'conteúdo' em Instrumentos Normativos de Descrição Arquivística

\begin{tabular}{|c|c|c|c|}
\hline INDA's & IDENTIFICAÇÃO & CONTEXTO & CONTEÚDO \\
\hline$M A D$ & NSA & NSA & $\begin{array}{l}\text { Forma, tipo e gênero dos documentos; indicado por } \\
\text { vocabulário controlado. }\end{array}$ \\
\hline$R A D$ & NP & NP & NP \\
\hline$I S A D G$ & $\begin{array}{l}\text { Código de referência; } \\
\text { Título. }\end{array}$ & NSA & $\begin{array}{l}\text { Estrutura dos documentos, assuntos e processos } \\
\text { administrativos. }\end{array}$ \\
\hline$D A C S$ & $\begin{array}{l}\text { Produtor como } \\
\text { ponto de acesso. }\end{array}$ & NP & $\begin{array}{l}\text { Funções que geraram o material descrito, data- } \\
\text { assunto, áreas geográficas, assuntos tópicos e sistemas } \\
\text { de arranjo. }\end{array}$ \\
\hline$N E D A$ & NSA & $\begin{array}{l}\text { Produtor como principal } \\
\text { ponto de acesso; }\end{array}$ & NSA \\
\hline$N O B R A D E$ & $\begin{array}{l}\text { Código de referência } \\
\text { comor principal } \\
\text { ponto de acesso. }\end{array}$ & NSA & $\begin{array}{l}\text { Tipologia documental, assunto e estrutura da } \\
\text { informação. }\end{array}$ \\
\hline$O D A$ & $\begin{array}{l}\text { Título como principal } \\
\text { ponto de acesso; }\end{array}$ & NSA & $\begin{array}{l}\text { Tipologias documentais, assuntos, cargos, funções, } \\
\text { atividades, procedimentos administrativos, eventos, } \\
\text { pessoas coletivas, pessoas singulares e famílias. }\end{array}$ \\
\hline$N U D A$ & NSA & $\begin{array}{l}\text { Produtor como principal } \\
\text { ponto de acesso. }\end{array}$ & $\begin{array}{l}\text { Conteúdo evidencia o assunto da unidade de } \\
\text { descrição. }\end{array}$ \\
\hline
\end{tabular}

Apêndice B - Caracterização de 'contexto’ em Instrumentos Normativos de Descrição Arquivística

\begin{tabular}{|l|l|l|l|}
\hline INDA's & IDENTIFICAÇÃO & CONTEXTO & CONTEÚDO \\
\hline TÁtulo representa & $\begin{array}{l}\text { Contexto é representado pela história } \\
\text { administrativa ou biografia, história arquivistica } \\
\text { e procedência }\end{array}$ & NSA \\
\hline contexto. & NP & NP & NP \\
\hline ISADG & NSA & $\begin{array}{l}\text { Contexto é representado pelo produtor, } \\
\text { história administrativa ou biografia, história } \\
\text { arquivística e procedência }\end{array}$ & NSA \\
\hline DSCS & NSA & NP & NSA \\
\hline NEDA & NSA & $\begin{array}{l}\text { Contexto é representado pelo produtor } \\
\text { Contexto é representado pelo produtor, } \\
\text { história administrativa ou biografia, história } \\
\text { arquivística e procedência }\end{array}$ & NSA \\
\hline NOBRADE & NSA & $\begin{array}{l}\text { Contexto é representado pelo produtor, } \\
\text { história administrativa ou biografia, história } \\
\text { custodial e arquivistica. }\end{array}$ & NSA \\
\hline ODA & NSA & $\begin{array}{l}\text { Contexto é representado pelo produtor, } \\
\text { origem e custódia, frente à realidade política, } \\
\text { histórica e/ou social. }\end{array}$ & NSA \\
\hline NUDA & & \\
\hline
\end{tabular}

